\title{
Risk factors associated with the development of perinatal asphyxia in neonates at the Hospital Universitario del Valle, Cali, Colombia, 2010-2011
}

\author{
Javier Torres-Muñoz, Christian Rojas, Diana Mendoza-Urbano, \\ Darly Marín-Cuero, Sandra Orobio, Carlos Echandía \\ Grupo INSIDE, Departamento de Pediatría, Facultad de Medicina, Universidad del Valle, Cali, Colombia
}

\begin{abstract}
Introduction: Perinatal asphyxia is one of the main causes of perinatal mortality and morbidity worldwide and it generates high costs for health systems; however, it has modifiable risk factors.

Objective: To identify the risk factors associated with the development of perinatal asphyxia in newborns at Hospital Universitario del Valle, Cali, Colombia.

Materials and methods: Incident cases and concurrent controls were examined. Cases were defined as newborns with moderate to severe perinatal asphyxia who were older than or equal to 36 weeks of gestational age, needed advanced resuscitation and presented one of the following: early neurological disorders, multi-organ commitment or a sentinel event. The controls were newborns without asphyxia who were born one week apart from the case at the most and had a comparable gestational age. Patients with major congenital malformations and syndromes were excluded.

Results: Fifty-six cases and 168 controls were examined. Premature placental abruption (OR=41.09; $95 \% \mathrm{Cl}: 4.61-366.56)$, labor with a prolonged expulsive phase (OR=31.76; 95\% $\mathrm{Cl}: 8.33-121.19)$, lack of oxytocin use $(\mathrm{OR}=2.57 ; 95 \% \mathrm{Cl}$ : $1.08-6.13)$ and mothers without a partner $(\mathrm{OR}=2.56 ; 95 \% \mathrm{Cl}$ : 1.21-5.41) were risk factors for the development of perinatal asphyxia in the study population. Social difficulties were found in a greater proportion among the mothers of cases.

Conclusions: Proper control and monitoring of labor, development of a thorough partograph, and active searches are recommended to ensure that all pregnant women have adequate prenatal care with the provision of social support to reduce the frequency and negative impact of perinatal asphyxia.
\end{abstract}

Key words: Asphyxia neonatorum; hypoxia, brain; abruptio placentae; prenatal care; oxytocin; fetal monitoring.

doi: http://dx.doi.org/10.7705/biomedica.v37i1.2844

Factores de riesgo asociados con el desarrollo de asfixia perinatal en neonatos en el Hospital Universitario del Valle, Cali, Colombia, 2010-2011

Introducción. La asfixia perinatal constituye una de las principales causas de morbilidad y mortalidad perinatal en el mundo, tiene factores de riesgo modificables y genera altos costos para los sistemas de salud.

Objetivo. Determinar los factores de riesgo asociados al desarrollo de asfixia perinatal en recién nacidos en el Hospital Universitario del Valle, Cali, Colombia.

Materiales y métodos. Se llevó a cabo un estudio de casos incidentes y controles concurrentes. Los casos se definieron como neonatos con asfixia perinatal moderada a grave, de edad de gestación mayor o igual a 36 semanas, que requirieron reanimación avanzada y presentaron, al menos, una de las siguientes condiciones: alteraciones neurológicas tempranas, falla orgánica múltiple o aparición de un evento centinela. Los controles se definieron como neonatos sin diagnóstico de asfixia, nacidos hasta con una semana de diferencia con respecto al caso y de edad de gestación comparable. Se excluyeron los pacientes con malformaciones congénitas mayores y síndromes.

Resultados. Se estudiaron 56 casos y 168 controles. El desprendimiento prematuro de la placenta (odds ratio, $\mathrm{OR}=41,09 ; \mathrm{IC}_{95 \%} 4,61-366,56$ ), un trabajo de parto con fase expulsiva prolongada (OR=31,76; $\left.\mathrm{IC}_{95 \%} 8,33-121,19\right)$, no usar oxitocina $\left(\mathrm{OR}=2,57 ; \mathrm{IC}_{95 \%} 1,08-6,13\right)$ y ser madre soltera $\left(\mathrm{OR}=2,56 ; \mathrm{IC}_{95 \%}\right.$ $1,21-5,41)$ fueron factores de riesgo para el desarrollo de asfixia perinatal en la población bajo estudio. En las madres de los casos se encontraron dificultades sociales en mayor proporción.

\footnotetext{
Author's contributions:

Javier Torres-Muñoz and Christian Rojas: study design and analysis, writing of the manuscript

Diana Mendoza-Urbano and Darly Marín-Cuero: data collection

Sandra Orobio: statistical analysis

Carlos Echandía: analysis and writing of the manuscript
} 
Conclusiones. Se recomienda un control adecuado y una vigilancia apropiada del trabajo de parto, hacer un estricto partograma, y una búsqueda activa, de manera que cada mujer embarazada tenga un adecuado control prenatal y reciba apoyo social.

Palabras clave: asfixia neonatal; hipoxia encefálica; desprendimiento prematuro de la placenta; atención prenatal; oxitocina; monitorización fetal.

doi: http://dx.doi.org/10.7705/biomedica.v37i1.2844

Perinatal asphyxia is a clinical syndrome that affects multiple organs and primarily results in hypoxic ischemic encephalopathy. The latter is defined as the lack of oxygen in the circulatory system of the fetus or neonate and causes multiple alterations in the newborn's neurological function, thereby generating disability and neurodevelopment disorders, as well as major social, emotional and economic losses (1).

Events due to perinatal asphyxia are estimated to occur in approximately 2 to 4 per 1,000 newborns worldwide who are alive at term. After prematurity, perinatal asphyxia is considered to be the main cause of neonatal mortality $(2,3)$. It is estimated that over one million newborns who survive asphyxia develop cerebral palsy, epilepsy, learning disabilities and other developmental problems, with longterm sequelae $(2,4,5)$.

In Colombia, neonatal mortality is responsible for $57 \%$ of deaths in the first year of life, with an infant mortality rate of 24 deaths per 1,000 live births; the department of Valle del Cauca has reported a rate of infant mortality of 12.4 per 1,000 live births $(6,7)$. In the neonatal intensive care unit of the Hospital Universitario del Valle, perinatal asphyxia was the third most common cause of admission in the first half of 2006 (13.2\% of all patients seen); in the same period in 2007 , the corresponding rate was $12.4 \%$. During the first half of 2006, 73 children in this unit died, $23.3 \%$ of them due to perinatal asphyxia as the basic cause and $31.5 \%$ as the final cause; in the same period in 2007, 100 children died, of whom $23 \%$ died due to perinatal asphyxia as the basic cause and $31.3 \%$ as the final cause (8).

Some risk factors for the development of perinatal asphyxia have been reported to be preventable, and they were not always the same for the different populations under study; this difference in results suggests that these factors have not been fully extrapolated (9-12).

Corresponding author:

Javier Torres-Muñoz, Calle $5 \mathrm{~N}^{\circ}$ 36-08, Cali, Colombia

Phone: (572) 5587004

jtmml@hotmail.com

Received: 01/06/15; accepted: 01/06/16
The fourth Millennium Development Goal stated that by 2015 , child mortality should be reduced by 2/3 among children under five, including deaths due to perinatal asphyxia. This study aimed to identify the antepartum and intrapartum risk factors associated with the development of this event, so as to establish rational and effective strategies addressing factors deemed to be as preventable.

\section{Materials and methods \\ Design}

We used a case-control design, with a relation of one case per three controls.

\section{Study population}

We included new cases of newborns with diagnosed perinatal asphyxia who were admitted to the intensive care unit at Hospital Universitario del Valle, a level III care unit in the city of Cali, between March 2010 and August 2011.

\section{Case definition}

Cases were defined as newborns diagnosed with moderate and severe perinatal asphyxia with a gestational age equal to 36 weeks or more who required advanced resuscitation and presented at least one of the following clinical signs: early neurological disorders, multi-organ commitment or the presence of a sentinel event. The $\mathrm{pH}$ results were not assessed in all cases, as this information was not found in the medical records.

\section{Definition of controls}

Controls were defined as newborns without asphyxia that were born one week apart of the case at the most, with comparable gestational age.

\section{Inclusion and exclusion criteria}

We included patients with a Ballard gestational age older than or equal to 36 weeks who required advanced neonatal resuscitation and exhibited at least one of the following:

- Neonatal neurological signs in the first 24 hours of life (convulsion, coma, hypotonia, etc.), not attributable to another cause, confirmed by pediatric neurologic evaluation and regardless of umbilical cord blood $\mathrm{pH}$. 
- Multi-organic commitment not attributable to another cause (central nervous system, renal, pulmonary, cardiovascular, gastrointestinal, metabolic or hematologic).

- Presence of an event attributable to health care that compromised the infant's life or caused serious damage (sentinel event).

- We excluded the following patients:

- Patients with major congenital malformations

- Patients with syndromes (Down, hypotonic child)

- Patients with neurological defects explainable by a condition other than perinatal asphyxia (electrolytic alteration, inborn error of metabolism)

- Patients with incomplete study data.

\section{Sample size}

Based on the variable lack of prenatal care, which had the largest sample size, an OR of 2.05, a ratio p1 of 0.191 for pregnant women with newborns in the case group, a ratio p2 of 0.103 for pregnant women with newborns in the control group, an alpha type I error of $5 \%$, a power of $80 \%$ and three controls per case, we estimated the sample size to include 56 cases and 168 controls.

\section{Description}

The degree of asphyxia was documented in the medical records and/or by examinations conducted by some of the members of the research team. Researchers attended the neonatal intensive care unit at Hospital Universitario del Valle daily and selected new cases diagnosed with moderate to severe perinatal asphyxia. When a newborn met the case definition and inclusion criteria, a search began for three infants in the same neonatal unit who did not have the condition, were of a similar gestational age, and were born a week apart of the case at the most (concurrent).

\section{Analysis plan}

After validating the records in the database, a multiple correspondence factorial analysis of maternal social and demographic variables (qualitative) was conducted using the FactoClass in R 2.10 statistical software. Factorial analysis summarizes the set of variables studied by new data (index) that are linear combinations of the same.

Then we performed a bivariate analysis testing each of the maternal independent variables, antepartum, intrapartum and neonatal, against the outcome variable (presence or absence of moderate or severe perinatal asphyxia) using odds ratios (OR) and $95 \%$ confidence intervals to indicate risk. We also tested collinearity between the variables associated with the outcome.

Subsequently, the variables were selected using the backward method to adjust the logistic regression model to estimate the risk that a newborn exposed to the identified factors would suffer from perinatal asphyxia. The final adjusted model was assessed by a diagnostic test that determined how the new test (adjusted model) classified the newborns in the sample in comparison to the gold standard (observed).

\section{Ethical aspects}

The protocol was approved by the Human Ethics Committee of the Faculty of Health at Universidad del Valle and the Ethics Committee at Hospital Universitario del Valle.

\section{Results}

In the 17 months of study, we found 56 cases with perinatal asphyxia and 168 controls. Four cases were excluded because of a lack of maternal social and demographic, antepartum or intrapartum information.

The general characteristics of the mothers and newborns were similar for cases and controls, with the exception of marital status; a higher proportion of mothers of cases did not have a partner compared with mothers of controls (table 1 ).

Characterizing the social and demographic variables of cases and controls using multiple correspondence factorial analysis, mothers of cases were found to have a more unstable situation, as they

Table 1. Maternal and newborn sociodemographic characteristics

\begin{tabular}{lccc}
\hline Characteristics & Cases & Controls & $\mathbf{p}$ \\
\hline Maternal age (years) & $23.4(6.1)$ & $24.8(7,2)$ & 0.3237 \\
Rural origin (\%) & 17.8 & 11.3 & 0.2073 \\
No education (\%) & 3.5 & 2.9 & 0.5579 \\
$\begin{array}{l}\text { Unaffiliated to health } \\
\text { care (\%) }\end{array}$ & 64.2 & 75 & 0.1215 \\
$\begin{array}{l}\text { No partner (\%) } \\
\text { Neonate }\end{array}$ & 48.2 & 32.1 & 0.0306 \\
Male (\%) & 64.3 & 48.8 & 0.0637 \\
$\begin{array}{l}\text { Gestational age } \\
\text { (weeks) }\end{array}$ & $38.8(1,5)$ & $38.8(1.3)$ & 0.8139 \\
$\begin{array}{l}\text { Weight at birth (g) } \\
\text { Small for gestational }\end{array}$ & $3,005(509.4)$ & $3,087(485.1)$ & 0.2964 \\
age (\%) & 10.7 & 4.7 & 0.2804 \\
& \multicolumn{4}{c}{}
\end{tabular}


were single mothers with no affiliation to the social security system and had a low level of education (figure 1).

Of the 56 cases, $33(58.9 \%)$ were classified as moderate perinatal asphyxia with Sarnat II, and 23 $(41.1 \%)$ were considered to have severe perinatal asphyxia with Sarnat III. Of the 33 infants classified as Sarnat II and the 23 as Sarnat III, 12 (36.3\%) and $19(82.6 \%)$, respectively, presented with multiorgan dysfunction.

The bivariate analysis showed that 11 independent variables were significantly associated with the presence of moderate to severe perinatal asphyxia and were considered in the selection of variables for the logistic regression model (table 2).

The variable insufficient prenatal care (mothers with less than three prenatal visits) showed a borderline, non-significant association with the presence of the condition: OR=0.33 (95\% Cl: 0.09 to $1.03 ; p=0.036)$. We examined the associations among these 11 factors and found that delivery in

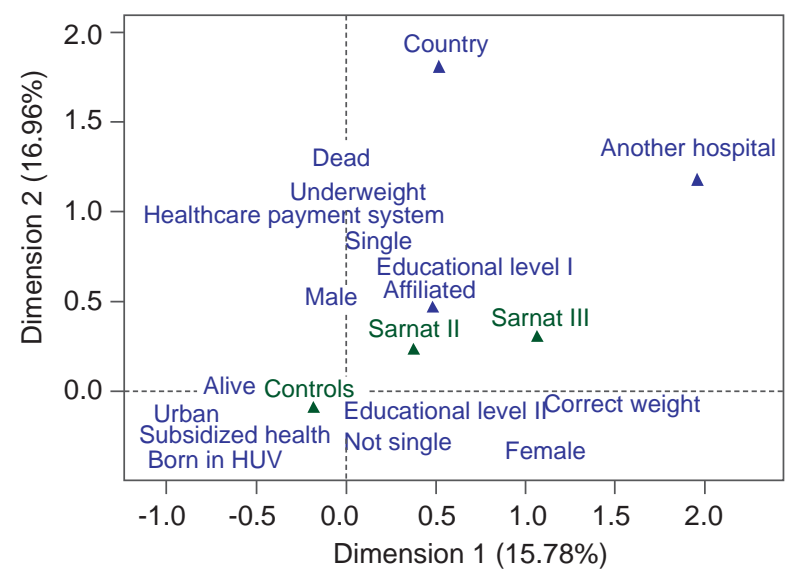

Figure 1. Characterization of neonatal and sociodemographic variables by multiple correspondence factorial analysis

Table 2. Variables significantly associated with perinatal asphyxia

\begin{tabular}{lccc}
\hline Associated variable & Crude OR & \multicolumn{2}{c}{ 95\%IC } \\
\hline Childbirth at another institution & 66.8 & $8.87-1390.7$ \\
Prolonged expulsive phase & 23.9 & $6.18-108.7$ \\
Premature placental abruption & 23.8 & $2.84-$ & 528.3 \\
Cesarean birth & 12.9 & $4.95-$ & 34.86 \\
Maternal morbidity & 5.6 & $1.24-$ & 35.39 \\
Amniotic fluid meconium & 4.2 & $2.15-$ & 8.49 \\
No use of oxytocin & 2.9 & $1.34-$ & 6.78 \\
No drugs & 2.7 & $1.39-$ & 5.4 \\
No partogram & 2.2 & $1.14-$ & 4.45 \\
No partner & 1.9 & $1.01-$ & 3.81 \\
Primiparous & 1.9 & $1.02-$ & 3.79 \\
\hline
\end{tabular}

another institution was associated with seven of the 11 variables, cesarean delivery was associated with six, and meconium amniotic fluid was associated with three, and, thus, it was not entered into the logistic regression model.

As for the remaining variables, in the correlation matrix using Spearman's method, the highest correlation was 0.11 between the variables nonrealization of partograph, labor with a prolonged expulsive phase and lack of oxytocin use.

The estimation of parameters to include in the regression model with the formula $m=3 n 1{ }^{*} n 2$ $/ \mathrm{n}=3$ (56) (158) / $224=126 / 10$ resulted in 12 parameters as possible candidates to enter into the model. The final logistic regression model showed that the risk factors associated with the development of perinatal asphyxia in the study population were as follows: Premature placental abruption (OR=41.09; 95\% Cl: 4.61-366.56), labor with a prolonged expulsive phase $(\mathrm{OR}=31.76 ; 95 \%$ Cl: 8.33-121.19), lack of use of oxytocin (OR: 2.57; $95 \% \mathrm{Cl}: 1.08-6.13)$ and mothers without a partner $(\mathrm{OR}=2.56 ; 95 \% \mathrm{Cl}: 1.21-5.41)$ (table 3).

The final logistic regression equation was as follows: perinatal asphyxia (yes/no) $=-2.71+3.71^{*}$; premature placental abruption $+3.46^{*}$; labor with prolonged expulsive phase $+0.94^{*}$; no oxytocin + $0.93^{*}$; no partner + error. The diagnostic test of the adjusted logistic regression model indicated that the final model correctly classified $49.9 \%(24 / 56)$ of the cases, a percentage that corresponded to the model sensitivity. The test also indicated that the model correctly classified most of the controls, with a specificity of $97.6 \%(164 / 168)$. Globally, the rate of correct classification of neonates studied in the fitted model was $83.9 \%(24+164$ / 224).

The average days of hospital stay among the cases was 12.4 days $(\mathrm{SD}=16.5)$ and 2.8 days $(1.8)$ among the controls. Eight cases died (14.2\%); additionally, seven of the $23(30.4 \%)$ were classified as Sarnat III, and one of the $33(3 \%)$ was classified as Sarnat II.

Table 3. Final logistic regression model

\begin{tabular}{lrrrr}
\hline Variable & Beta & $\begin{array}{c}\text { Adjusted } \\
\text { OR }\end{array}$ & 95\% Cl \\
\hline Intercept & -2.71 & 0.07 & $0.03-$ & 0.16 \\
Premature placental abruption & 3.71 & 41.09 & $4.61-366.56$ \\
Prolonged expulsive phase & 3.46 & 31.77 & $8.33-121.19$ \\
No use of oxytocin & 0.94 & 2.57 & $1.08-$ & 6.13 \\
No partner & 0.93 & 2.56 & $1.21-$ & 5.41 \\
\hline
\end{tabular}




\section{Discussion}

In this study of incident cases and concurrent controls, two intrapartum risk factors were found to have a very strong significant association with the presence of moderate and severe perinatal asphyxia in newborns: Premature placental abruption $(\mathrm{OR}=$ $41)$ and labor with a prolonged expulsive phase (OR=31.7).

Premature placental abruption has been associated with prenatal asphyxia and neonatal mortality in previous studies $(9,10)$. In a retrospective cohort study conducted in 2012, Martínez, et al., examined perinatal morbidity and the rate of asphyxia in infants exposed to intrapartum sentinel events and found that premature placental abruption, which occurred in $11 \%$, was significantly associated with the development of hypoxic ischemic encephalopathy (13). Furthermore, the degree of separation of the placenta has been linked with the risk of stillbirth (14).

No association was found between labor with a prolonged expulsive phase and the development of perinatal asphyxia in previous studies; however, triggers of a prolonged phase, such as abnormal fetal presentations (breech presentation, instrumental delivery, dystocia, persistent occiput posterior presentation, head circumference greater than the 97th percentile), have been previously related to the occurrence of this condition $(9,13,15)$.

The omission of a partograph during labor was also found to be a factor significantly associated with the presence of perinatal asphyxia (OR=2.25; 95\% $\mathrm{Cl}: 1.14-4.45)$, but it was excluded in the process of defining the final model. Without proper control and monitoring of labor with an appropriate partograph, it is not possible to diagnose in time two events as powerful as premature placental abruption and labor with a prolonged expulsive phase.

Another intrapartum risk factor that showed a weaker association with the presence of perinatal asphyxia was not using oxytocin during labor $(\mathrm{OR}=2.57)$. Previous studies found that labor needed to be monitored in order to define the appropriate use of oxytocin $(9,16)$. Not using oxytocin when indicated could lead to increased risks and prolonged labor time. Other studies are needed to properly assess and determine the associations of maternal reception of oxytocin during labor with perinatal asphyxia.

The fourth risk factor in this study that was significantly associated with the development of perinatal asphyxia was being a mother without partner $(\mathrm{OR}=2.56)$; this factor represents a state of vulnerability for the mother-fetus dyad. Being a single mother, not being affiliated to the social security system and having a low level of education were found in greater proportion among mothers of cases in the multiple correspondence factorial analysis, indicating that social difficulties can endanger the normal development of pregnancy. In an investigation by Milson, et al., in Sweden (9), being single was found to be a risk factor associated with the development of perinatal asphyxia.

Additionally, the lack of prenatal care or insufficient prenatal care with less than three visits during pregnancy showed a borderline association and was not significantly associated with the development of perinatal asphyxia among the infants in this study; however, in the literature, these factors have shown a clear relationship with poor prognosis of pregnancy $(17,18)$.

Mortality rate for cases in this study was $15 \%$, mostly among infants with severe perinatal asphyxia who were classified as Sarnat III. In a descriptive study conducted at the Cirena Neonatology Unit at Hospital Universitario del Valle in 2008, perinatal asphyxia prevalence was $19 \%$, and the most frequent pathology in the mother was hypertensive disorder associated with pregnancy (36.1\%). The highest mortality was evident in patients with Sarnat III hypoxic ischemic encephalopathy $(71.4 \%)(19,20)$.

This study showed that two intrapartum events were strongly associated with the presence of perinatal asphyxia. Therefore, appropriate tracing and monitoring of labor should be increased, partographs to identify abnormalities or delays in labor should be strictly performed, and the appropriate and timely use of oxytocin for stimulation should be considered. Primary care institutions should make timely referrals to specialists for optimal care of pregnant women with risk factors.

All neonates diagnosed with asphyxia were included regardless of their demographic characteristics; therefore, the results are applicable to any field of healthcare with similar demographic characteristics and health systems. The social and economic difficulties of mothers were also found to be associated with the presence of perinatal asphyxia, characteristics which are relatively frequent in our setting, especially among lower-income populations. An active search must be implemented to ensure that all pregnant women receive adequate prenatal care, including social support and control of these risk situations. 
The results of this study were based on routine physical evaluations of transferred babies born in other institutions, where the lack of resources made it difficult to obtain $\mathrm{pH}$ blood levels within the first hour, which is a weakness of the study, and indicates the need for medical groups to perform $\mathrm{pH}$ blood level tests in a timely manner, as this is a very important test for the diagnosis of this condition.

\section{Conflicts of interest}

The authors declare that there are no conflicts of interest regarding the contents of this manuscript.

\section{Financial support}

This work was financed entirely by Universidad del Valle.

\section{References}

1. Robertson $\mathbf{C M}$, Perlman M. Follow-up of the term infant after hypoxic-ischemic encephalopathy. Paediatr Child Health. 2006;11:278-82.

2. GBD 2013 Mortality and Causes of Death Collaborators. Global, regional, and national age-sex specific all-cause and cause-specific mortality for 240 causes of death, 1990-2013: A systematic analysis for the Global Burden of Disease Study 2013. Lancet .2015;385:117-71. http://dx.doi. org/10.1016/S0140-6736(14)61682-2

3. Lawn JE, Cousen S, Zupan J, Lancet Neonatal Survival Steering Team. 4 million neonatal deaths: When? Where? Why? Lancet. 2005;365:891-900. http://dx.doi.org/10.1016/ S0140-6736(05)71048-5

4. García AA, García JA, Blanco BD, Quero JJ, Esqué MT, Figueras AJ. Asfixia perinatal y parálisis cerebral. An Esp Pediatric. 2000;53:40-2.

5. Moss W, Darmstadt L, Marsh DR, Black RE, Santosham M. Research priorities for the reduction of perinatal and neonatal morbidity and mortality in developing country communities. J Perinatol. 2002;22:484-95. http://dx.doi. org/10.1038/sj.jp.7210743

6. Clark SM, Basraon SK, Hankins GD. Intrapartum asphyxia, neonatal encephalopathy, cerebral palsy, and obstetric interventions in the term and near-term infant. NeoReviews. 2013;14:e13-21. http://dx.doi.org/10.1542/neo.14-1-e13

7. Centro Latinoamericano de Perinatología y Desarrollo Humano, CLAP. Estadísticas de la Región de América Latina y Caribe. Montevideo: CLAP. Fecha de consulta: 29 de marzo de 2005. Disponible en: http://www.clap.ops-oms. org/web_2005/estadisticas\%20de\%20la\%20region/index.htm

8. Gartner ME. Boletín estadístico neonatal 2007. Comparación primer semestre 2006-2007. Cali: Fundación CIRENA; 2007. p. 5-6.
9. Milsom I, Ladfors L, Thiringer K, Niklasson A, Thornberg E. Influence of maternal, obstetric and fetal risk factors on the prevalence of birth asphyxia at term in a Swedish urban population. Acta Obstet Gynecol Scand. 2002;81:909-17. http://dx.doi.org/10.1034/j.1600-0412.2002.811003.x

10. Majeed R, Memon Y, Majeed F, Shaikh NP, Rajar UD. Risks factors of birth asphyxia. J Ayub Med Coll Abbottabad. 2007;19:67-71.

11. Volpe JJ. Hypoxic-ischemic encephalopathy: Clinical aspects. In: Volpe JJ, editor. Neurology of the Newborn. Philadelphia, PA: Elsevier Saunders; 2008. p. 400-80.

12. Badawi N, Kurinczuk JJ, Keogh JM, Alessandri LM, O'Sullivan F, Burton PR, et al. Intrapartum risk factors for newborn encephalopathy: The Western Australian casecontrol study. BMJ. 1998;317:1554-8.http://dx.doi.org/10. 1136/bmj.317.7172.1554

13. Martínez BM, Madero R, González A, Quero J, García AA. Perinatal morbidity and risk of hypoxic-ischemic encephalopathy associated with intrapartum sentinel events. Am J Obstet Gynecol. 2012;206:148.e1-7. http://dx.doi.org/10. 1016/j.ajog.2011.09.031

14. Ananth CV, Berkowitz GS, Savitz DA, Lapinski RH. Placental abruptio and adverse perinatal outcomes. JAMA. 1999;282:1646-51. http://dx.doi.org/10.1001/jama.282.17. 1646.

15. Ellis M, Manandhar N, Manandhar DS, Costello AM. Risk factors for neonatal encephalopathy in Kathmandu, Nepal, a developing country: Unmatched case control study. BMJ. 2000;320:1229-36. http://dx.doi.org/10.1136/bmj.320. 7244.1229

16. Hayes BC, McGarvey C, Mulvany S, Kennedy J, Geary MP, Matthews TG, et al. FRCPCH, a case-control study of hypoxic-ischemic encephalopathy in newborn infants at $>36$ weeks gestation. Am J Obstet Gynecol. 2013;209:e-1-29. http://dx.doi.org/10.1016/j.ajog.2013.03.023

17. Schoeps D, Almeida MF, Alencar GP, França Jr I, Novaes HM, Siqueira AA, et al. Risk factors for early neonatal mortality. Rev Saúde Pública. 2007;41:1013-22. http://dx. doi.org/10.1590/S0034-89102007000600017

18. Daripa M, Caldas HM, Flores LP, Waldvogel BC, Guinsburg R, de Almeida MF. Perinatal asphyxia associated with early neonatal mortality: Populational study of avoidable deaths. Rev Paul Pediatr. 2013;31:37-45. http:// dx.doi.org/10.1590/S0103-05822013000100007

19. Torres J. Caracterización de los recién nacidos con asfixia perinatal en un hospital universitario de tercer nivel en Colombia. Revista Gastrohnup. 2013;15:S4-S11.

20. Muller AJ, Marks JD. Hypoxic ischemic brain injury: Potential therapeutic interventions for the future. Neoreviews. 2014;15:e177-86. http://dx.doi.org/10.1542/neo.15-5-e177 